\title{
Side Effects and Management: Osteonecrosis of Jaw and Acute Phase Reaction
}

\author{
(1) Başak OYAN
}

Department of Internal Medicine, Section of Medical Oncology, Acıbadem University, Acıbadem Altunizade Hospital, Istanbul-Turkey

\section{Introduction}

Both bisphosphonates and denosumab used in patients with bone metastases have common side effects as well as side effects specific to their drug class.

\section{Osteonecrosis of theJaw (ONJ)}

Drug-induced osteonecrosis of the jaw is a form of avascular necrosis. It may develop as a side effect to both bisphosphonates and denosumab. Although not common, it is a serious adverse event. The possibility of developing ONJ in the first year of medication is less than 2\%.[1-3] Although the risk with denosumab treatment is slightly higher than with bisphosphonates $(1.9 \%$ vs. $1.3 \%)$, the difference is not statistically significant.

In patients on bone-targeted drugs, the most important risk factor is an invasive dental procedure.[4] The most important risk factor for ONJ, a condition difficult to treat, is avoidance of invasive dental procedures. All patients should undergo a comprehensive dental check-up before starting bone-targeted drugs, and complete the required invasive interventions before starting treatment.[4] After starting the treatment, interventions such as tooth extraction and dental implants should be avoided as much as possible.[4] Less invasive treatments, such as dental cleaning, decay treatment, and root canal treatment, may be performed. If tooth extraction or interventional procedure becomes essential, treatment should be paused for a while. Although the optimal time for such pause is undefined, the most common recommendation is to interrupt the treatment up to three months prior and three months after tooth extraction.

Few conservative treatment methods such as limited debridement, use of antibiotics, and mouthwash are recommended for patients with osteonecrosis of the jaw. $[4,5]$

\section{Acute Phase Reaction}

Transient flu-like symptoms may develop after the first dose or first few doses in patients receiving intravenous zoledronic acid or pamidronate.[1,6] This syndrome is a typical acute phase response characterized by fever, chills, headache, myalgia, and arthralgia. It is is due to transient cytokine release. These symptoms are usually mild and resolve spontaneously within a few days. Acetaminophen can be used for prevention and symptomatic treatment. Sometimes, the symptoms may continue in repeated applications. In such a case, treatment can be switched to denosumab.

\section{References}

1. Stopeck AT, Lipton A, Body JJ, Steger GG, Tonkin K, de Boer RH, et al. Denosumab compared with zoledronic acid for the treatment of bone metastases in patients with advanced breast cancer: a randomized, double-blind study. J Clin Oncol 2010;28(35):5132-9.

2. Henry DH, Costa L, Goldwasser F, Hirsh V, Hungria V, Prausova J, et al. Randomized, double-blind study of denosumab versus zoledronic acid in the treatment of bone metastases in patients with advanced cancer (excluding breast and prostate cancer) or multiple
Accessible online at: www.onkder.org

OPEN ACCESS This work is licensed under a Creative Commons Attribution-NonCommercial 4.0 International License.
Dr. Başak OYAN

Acıbadem Üniversitesi,

Acıbadem Altunizade Hastanesi,

İç Hastalıkları Anabilim Dalı,

Tıbbi Onkoloji Bölümü,

Istanbul-Turkey

E-mail: basak.uluc@acibadem.com 
myeloma. J Clin Oncol 2011;29(9):1125-32.

3. Fizazi K, Carducci M, Smith M, Damião R, Brown J, Karsh L, et al. Denosumab versus zoledronic acid for treatment of bone metastases in men with castrationresistant prostate cancer: a randomised, double-blind study. Lancet 2011;377(9768):813-22.

4. Van Poznak CH, Temin S, Yee GC, Janjan NA, Barlow WE, Biermann JS, et al. American Society of Clinical Oncology executive summary of the clinical practice guideline update on the role of bone-modifying agents in metastatic breast cancer. J Clin Oncol 2011;29(9):1221-7.

5. Coleman R, Hadji P, Body JJ, Santini D, Chow E, Terpos E, et al. Bone health in cancer: ESMO Clinical Practice Guidelines. Ann Oncol 2020;31(12):1650-63.

6. Olson K, Van Poznak C. Significance and impact of bisphosphonate-induced acute phase responses. J Oncol Pharm Pract 2007;13(4):223-9. 